\title{
A FRACTIONAL RATE MODEL OF LEARNING
}

\section{George Dassios, George Fragoyiannis and Konstantia Satrazemi}

Abstract. A fundamental principle of Cognitive Psychology states that the rate at which the human brain learns a certain amount of knowledge is proportional to the amount of knowledge yet to be learned. This is the so called pure memory or tabula raza law of learning. The mathematical formulation of this principle leads to a simple ordinary differential equation of the first order. Here we expand the existing mathematical model to a fractional differential equation which allows for a more realistic model having a much higher freedom to fit possible experimental data, as well as allowing for memory effects during the learning process. Two different definitions of the fractional derivative are used, one is the standard Riemann-Liouville global definition and the other is a local definition based on the choice of the unit that measures functional variation. A detailed comparison with the conventional model both at the analytical and the numerical level is included.

Mathematics subject classification (2010): 26A33, 34A08, 97C30. Keywords and phrases: learning model, fractional rate.

\section{REFERENCES}

[1] T. ABdeLjawad, On conformable fractional calculus, arXiv:1402.6892vl [math.DS] 27 feb 1014.

[2] B. ALDRIDGE, A mathematical model for mastery learning, Journal of Research in Science Teaching, vol. 20, pp. 1-17 (1983).

[3] D. Anderson And D. Ulness, Properties of the Katugmpola fractional derivative with potential application in quantum mechanics, Journal of Mathematical Physics, vol. 56, 063502 (2015).

[4] I. Antoniou AND F. Bosco, On the spectral properties of a Markov model for learning processes, International Journal of Modern Physics, vol. 11, pp. 213-220 (2000).

[5] R. ATKInson AND R. SHIFFrin, Mathematical Models for Memory and Learning, Institute for Mathematical Studies in the Social Sciences, Technical Report no. 79, Stanford University (1965).

[6] R. Bush And F. Mosteller, A mathematical model for simple learning, The Phychological Review, vol. 58, pp. 313-323 (1951).

[7] R. Herrmann, Fractional Calculus. An Introduction for Physicists, World Scientific, New Jersey (2014).

[8] U. Katugampola, A new approach to generalized fractional derivatives, Bulletin of Mathematical Analysis and Applications, vol. 4, pp. 1-15 (2014).

[9] A. Kilbas, H. SRivastava and J. Trujillo, Theory and Applications of Fractional Differential Equations, Elsevier, Amsterdam (2006).

[10] K. KolwankaR, Local fractional calculus: a review, arXiv:1307.0739v1 [nlin.CD] 2 July 2013.

[11] K. Oldham And J. Spanier, The Fractional Culculus, Academic Press, New York (1974).

[12] P. PREECE, Mathematical modeling of learning, Journal of Research in Science Teaching, vol. 21, pp. 953-955 (1984).

[13] I. Podlubney, Fractional Differential Equations, Academic Press, San Diego (1999).

[14] I. Podlubney, Geometric and physical interpretations of fractional differentiation and fractional integration, Fractional Calculus and Applied Analysis, vol. 5, pp. 367-386 (2002).

[15] D. Pritchard, Y.-J. LeE AND L. BAO, Mathematical learning models that depened on prior knowledge and instructional strategies, Physical Review Special Topics-Physics Education Research, vol. 4, 010109 (2008). 
[16] V. TANASOV, Local fractional derivatives of differentiable functions and integer-order derivatives or zero, International Journal of Applied and Computational Mathematics, DOI 10.1007/S40819-0150054-6.

[17] M. Wells, D. Hestenes And G. Swackhamer, A modeling method for high school physics instruction, American Journal of Physics, vol. 63, pp. 606-619 (1995). 